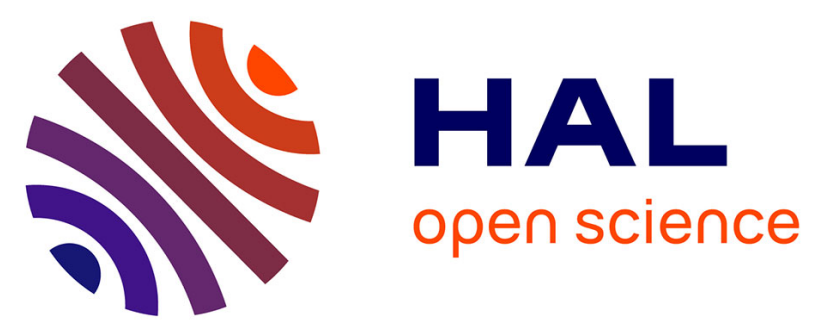

\title{
Atom transfer radical polymerization (ATRP) initiated by aryl diazonium salts: a new route for surface modification of multiwalled carbon nanotubes by tethered polymer chains
}

\author{
Tarik Matrab, Jérôme Chancolon, Martine Mayne-L'Hermite, Jean-Noël \\ Rouzaud, Guy Deniau, Jean-Paul Boudou, Mohamed M. Chehimi, Michel \\ Delamar
}

\section{- To cite this version:}

Tarik Matrab, Jérôme Chancolon, Martine Mayne-L'Hermite, Jean-Noël Rouzaud, Guy Deniau, et al.. Atom transfer radical polymerization (ATRP) initiated by aryl diazonium salts: a new route for surface modification of multiwalled carbon nanotubes by tethered polymer chains. Colloids and Surfaces A: Physicochemical and Engineering Aspects, 2006, 287 (1-3), pp.217-221. 10.1016/j.colsurfa.2006.05.028 . bioemco-00156637

\section{HAL Id: bioemco-00156637 https://hal-bioemco.ccsd.cnrs.fr/bioemco-00156637}

Submitted on 22 Jun 2007

HAL is a multi-disciplinary open access archive for the deposit and dissemination of scientific research documents, whether they are published or not. The documents may come from teaching and research institutions in France or abroad, or from public or private research centers.
L'archive ouverte pluridisciplinaire HAL, est destinée au dépôt et à la diffusion de documents scientifiques de niveau recherche, publiés ou non, émanant des établissements d'enseignement et de recherche français ou étrangers, des laboratoires publics ou privés. 


\title{
Atom transfer radical polymerization (ATRP) initiated by aryl diazonium salts: a new route for surface modification of multiwalled carbon nanotubes by tethered polymer chains
}

\author{
Tarik Matrab ${ }^{\mathrm{a}}$, Jérôme Chancolon ${ }^{\mathrm{b}}$, Martine Mayne L' hermite ${ }^{\mathrm{b}}$, Jean-Noël Rouzaud ${ }^{\mathrm{c}}$, \\ Guy Deniau ${ }^{\mathrm{d},}$ Jean-Paul Boudou ${ }^{\mathrm{e}}$. Mohamed M. Chehimi ${ }^{\mathrm{a}}, *$, Michel Delamar ${ }^{\mathrm{a}}$

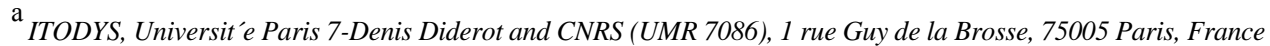 \\ ' Laboratoire de g'eologie de l'Ecole Normale Sup'erieure, 24 rue Lhomond, 75231 Paris, Cedex 05, France \\ d CEA Saclay, DSM-DRECAM-SPCSI, 91191 Gif sur Yvette Cedex, France

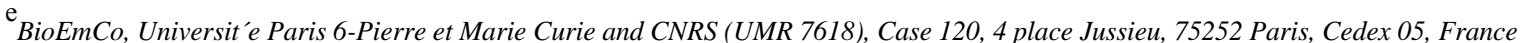

\begin{abstract}
We report for the first time on grafting of poly(n-methyl methacrylate), (PMMA), and polystyrene (PS) brushes by ATRP from the surface of aligned multiwalled carbon nanotubes (MWCNT) which were electrochemically treated with brominated aryl groups based on diazonium salts. The polymer brushes formed amorphous coatings, as evidenced by high-resolution transmission electron microscopy, by comparison to the nanotube structure. X-ray photoelectron spectroscopy (XPS) analysis confirmed the presence of PS and PMMA by their characteristic C1s and valence band features. Well-aligned MWCNT network allowed us to sheath individual MWCNTs with polymer brushes while keeping the initial MWCNT alignment structure. This method opens up new avenues for the elaboration of polymer/NT hybrids.
\end{abstract}

(C) 2006 Elsevier B.V. All rights reserved.

Keywords: Carbon nanotubes; Diazonium salts; Atom transfer radical polymerization (ATRP)

\section{Introduction}

Polymer brushes have recently attracted considerable attention because of their novel structures and properties $[1,2]$. Covalent attachment of polymer chains to the surface can be accomplished by either "grafting to" or "grafting from" techniques. "Grafting to" involves the bonding of a preformed end-functionalized polymer to reactive surface groups on the substrate. The "grafting from" technique involves the immobilization of initiators onto the substrate followed by in situ surface polymerization to generate the tethered polymer chains [2,3]. It has the advantage of preparing polymer brushes with high grafting density (up to $85 \mathrm{mg} / \mathrm{m}^{2}$ ) as compared to the "grafting to" method (about $1 \mathrm{mg} / \mathrm{m}^{2}$ ) [4]. Indeed, the attachment of a small number of chains hinders diffusion of additional

* Corresponding author. Tel.: +33 144276809; fax: +33 144276814.

E-mail address: chehimi@paris7.jussieu.fr (M.M. Chehimi). macromolecules to the surface, thereby leading to low grafting density. A high polymer chain density is actually of considerable importance when dealing with polymer-based biocompatible materials.

For better control of the molecular weight and the molecular weight distribution of the polymer chains, living radical, anionic, cationic, and ring-opening metathesis polymerizations have been used in "grafting from" methods [2]. Controlled radical polymerization, especially atom transfer radical polymerization (ATRP) [5] is the most used method to graft polymer chains of controlled molecular weight from, e.g. silicon wafers, gold particles, and polymer backbones. ATRP is indeed a versatile method in terms of choice of functional monomers, performance at moderate temperature $\left(100{ }^{\circ} \mathrm{C}\right.$ or less), in either aqueous or organic solvents [5]. A variety of polymeric materials can be obtained by ATRP ranging from simple linear macromolecules to more sophisticated architectures such as star brush copolymers [6]. Surface-initiated ATRP (SI-ATRP) [2] allows developing novel thermo-responsive systems [7]; 
for the control of cell adhesion [8]; separation materials based on nanofilms of molecularly imprinted polymer brushes [9], and dispersible carbon nanotubes in common solvents [10] to name but a few.

SI-ATRP can be performed using, e.g. initiator-functionalized silanes [5], thiols [11,12], plasma-treated polymers [13], polyelectrolyte macroinitiators [ 14] and streptavidin-biotin conjugates [15]. Recently, we have proposed that ATRP of vinyl monomers can be initiated by electro-grafted brominated aryl species based on diazonium salts at the surface conductive materials such as iron [16], doped ultrananocrystalline diamond [17] and glassy carbon [18]. The use of aryl diazonium salts is indeed a simple and elegant way of modifying conductive substrates such as metals, semi-conductors and carbon in view of elaborating molecular junctions in electronic circuits, biosensors, and protective layers against corrosion [19]. Particularly, grafting aryl groups was successfully achieved on glassy carbon [20], carbon felts [21], ultrananocrystalline diamond [22] and carbon nanotubes $[23,24]$. Moreover, they impart controlled interfacial properties to the host substrate such as hydrophilic/hydrophobic character [22], or dispersion in organic solvents [23a].

From the above, it is clear that electrografting halogenated aryl groups based diazonium salts onto carbon nanotubes should be a straightforward way of surface modification as compared to the traditional, harsh chemical attacks. Moreover, this electrochemical surface treatment step can be complemented by SIATRP in view of getting carbon nanotube-polymer hybrids. The preliminary nanotube covalent functionalization by aryl groups is thus of major importance to control the nanotube-polymer interface and therefore to get nanocomposites with improved physical properties. It is in this context that this study proposes an efficient way to graft polymer chains through the SI-ATRP method on carbon nanotubes.

In this communication, we report on the surface functionalization of multi-walled carbon nanotubes (MWCNT) by phenyl ethyl bromide groups following the electrochemical reduction of the corresponding diazonium salt ${ }^{\mathrm{BF}_{4}-},{ }_{+} \mathrm{N}_{2}-\mathrm{C}_{6} \mathrm{H}_{4}-$ $\mathrm{CH}_{2} \mathrm{CH}_{2}-\mathrm{Br}$ (D1). Aligned MWCNTs were grown on Si substrate by aerosol-assisted catalytic chemical vapour deposition [25]. MWCNT-modified Si wafers are amenable to electrochemical treatment and the as-obtained $\mathrm{BrCH}_{2} \mathrm{CH}_{2}-\mathrm{C}_{6} \mathrm{H}_{4}$-modified MWCNT (MWCNT-Br) served as a platform for the growth of polystyrene and poly(methyl methacrylate) (PS and PMMA, respectively) chains by ATRP. The MWCNT-polymer hybrids were characterized by transmission electron microscopy and Xray photoelectron spectroscopy (XPS).

\section{Experimental}

\subsection{Preparation of MWCNTs}

The MWCNT synthesis has been performed by aerosolassisted catalytic chemical vapour deposition (CCVD) process which has been described elsewhere [25]. Briefly, this process involves the use of solutions containing both liquid hydrocarbon and metal precursor. This method consists in producing and subsequently pyrolysing mixed liquid aerosols generated from the solutions. The starting solution is composed of ferrocene ( 5 wt.\%) dissolved in toluene and the aerosol, carried by an argon flow, is pyrolysed at $850{ }^{\circ} \mathrm{C}$ during $7 \mathrm{~min}$. Sample was grown on $n$-doped silicon substrate. It is composed of multi-walled carbon nanotubes perpendicularly aligned and attached to the substrate surface and looks like a carpet. The nanotube length reaches $130 \mu \mathrm{m}$ and the average inter-tube space is around $100 \mathrm{~nm}$. External diameter of carbon nanotubes is varying between 10 and $100 \mathrm{~nm}$.

\subsection{Synthesis of the diazonium salt $\mathrm{BF}_{4}{ }^{-}+\mathrm{N}_{2}-\mathrm{C}_{6} \mathrm{H}_{4}-\mathrm{CH}_{2}-\mathrm{CH}_{2}-\mathrm{Br}$}

The starting diazonium salt was synthesized in one pot from the commercially available 4-aminophenethyl alcohol (1 g) by heating at $150 ' \mathrm{C}$ in $48 \% \mathrm{HBr}(25 \mathrm{~mL})$ for $4 \mathrm{~h}$, then cooling to $0{ }^{\circ} \mathrm{C}$ to give a white precipitate. The diazotization is then achieved by the standard method that consists of adding $\mathrm{HBF}_{4}$ and $\mathrm{NaNO}_{2}$ (1.1 equivalent). The precipitated brown diazonium tetrafluoroborate was filtered and washed with $5 \% \mathrm{NaBF}_{4}$, methanol, and ether. ${ }^{1} \mathrm{H} \mathrm{NMR}$, $200 \mathrm{MHz}, \delta$ ppm: $3.35(\mathrm{t}, 2 \mathrm{H})$, benzylic protons; $3.47(\mathrm{t}, 2 \mathrm{H})$ ethylic proton; $7.87(\mathrm{~d}, 2 \mathrm{H}, J=8.8 \mathrm{~Hz})$ and $8.59(\mathrm{~d}, 2 \mathrm{H}, J=8.8$ $\mathrm{Hz}$ ), aromatic protons [ 3 to the diazonium function and to the benzylic carbon, respectively.

\subsection{Electrochemical treatment of multiwalled carbon nanotubes}

Electrochemical reduction of the diazonium salt was achieved by chronoamperometry for $300 \mathrm{~s}$, at a potential $300 \mathrm{mV}$ negative to the peak potential $(-138 \mathrm{mV} / \mathrm{SCE})$ (measured on glassy carbon). The Si wafer-supported MWCNT were then thoroughly sonicated in de-aerated ethanol. Some of the nanotubes were detached from the Si wafers due to this washing procedure. The as modified nanotubes are abbreviated by MWCNT-Br.

\subsection{Surface-Initiated ATRP of vinyl monomers}

The MMA, and styrene (Aldrich) were each distilled prior to polymerization. $N, N, N$ ', $N^{\prime \prime}, N^{\prime \prime}$-pentamethyldiethylenetriamine (PMDETA), $\mathrm{CuBr}, \mathrm{CuCl}$, and $\mathrm{CuCl}_{2}$ (Aldrich) were used as received. Surface-initiated ATRP was undertaken on the Si wafer-supported MWCNT-Br specimens.

For SI-ATRP of styrene, a 100-mL Schlenk flask equipped with a magnetic stir bar and sealed with a rubber septum was deoxygenated by a vacuum followed by back-filling with nitrogen three times. The $\mathrm{CuBr}$ powder (36.1 mg, $2.52 \times 10^{-4} \mathrm{~mol}$ ) and the MWCNT-coated Si wafers were introduced into the flask under a nitrogen flow. A mixture containing styrene $\left(13.5 \mathrm{~g}, 1.3 \times 10^{-1} \mathrm{~mol}\right)$, and PMDETA (26 mg, $\left.1.55 \times 10^{-4} \mathrm{~mol}\right)$, previously degassed, was added to the polymerization flask using a double-tipped needle under a nitrogen flow. The flask was placed in an oil bath at $110^{\prime} \mathrm{C}$ for $16 \mathrm{~h}$. The polymerization was stopped by cooling and opening the flask to expose the catalyst to air. For the growth of PMMA, the same procedure has been 

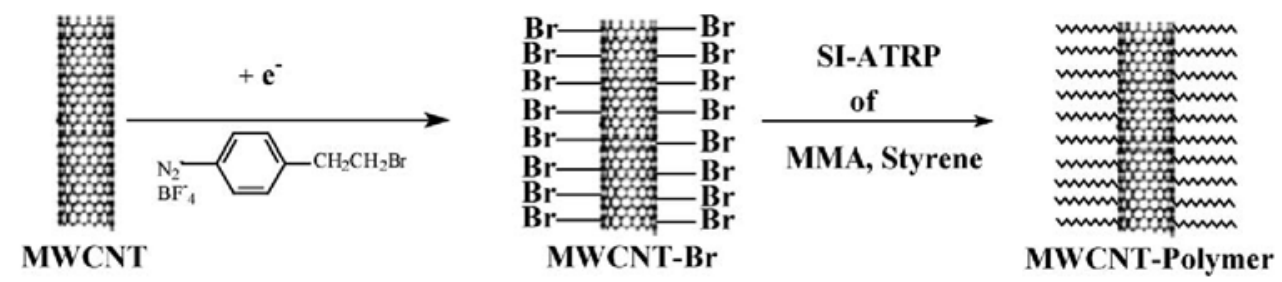

Scheme 1. Brominated initiators are attached to Pristine MWCNTs via electrochemical reduction of the corresponding diazonium salts. PS and PMMA chains are grafted by SI-ATRP from the MWCNT-Br platform.
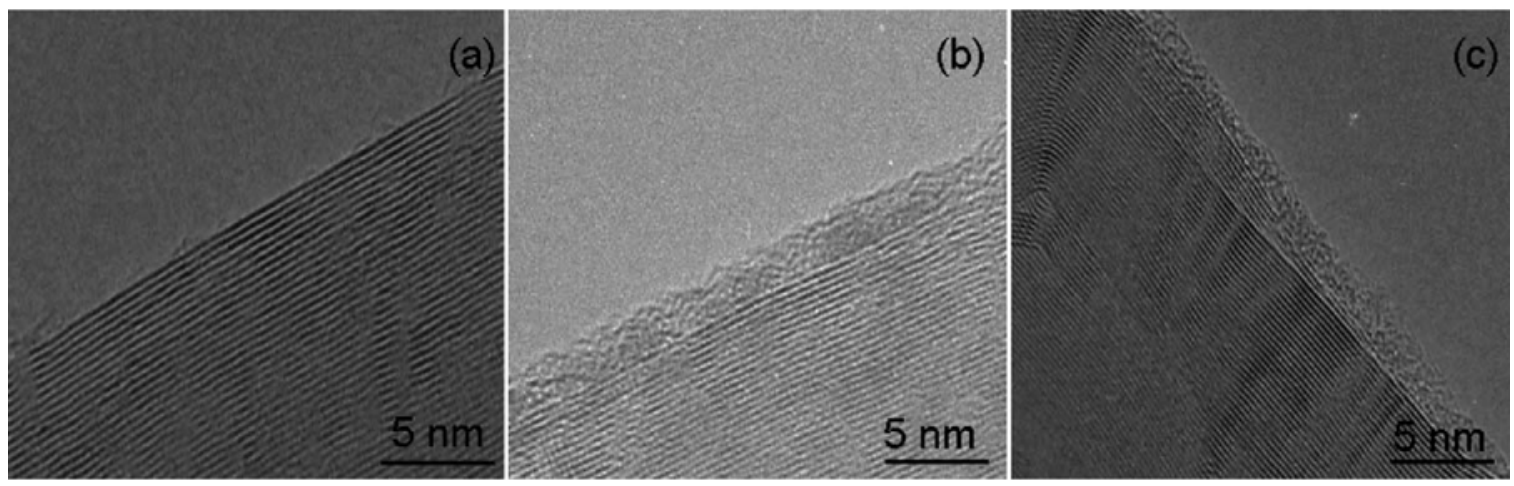

Fig. 1. HRTEM images of untreated MWCNT (a), MWCNT-PMMA (b), MWCNT-PS (c).

(18.0 mg, $\left.1.82 \times 10^{-4} \mathrm{~mol}\right), \mathrm{CuCl}_{2}\left(2.8 \mathrm{mg}, 2.08 \times 10^{-5} \mathrm{~mol}\right)$, methyl methacrylate $\left(14.1 \mathrm{~g}, 1.41 \times 10^{-1} \mathrm{~mol}\right)$, and PMDETA $\left(34.8 \mathrm{mg}, 2.01 \times 10^{-4} \mathrm{~mol}\right)$. The polymerization was carried out at 90 oc for $6 \mathrm{~h}$. The target molecular weights of the PS and PMMA chains were 42,500 and 32,500, respectively. The MWCNT-polymer hybrids were sonicated in dichloromethane for five periods of $5 \mathrm{~min}$.

It was observed that during the SI-ATRP process, nanotube bundles were detached from the Si wafer. After the washing procedure following ATRP, almost the majority of nanotubes were detached from the surface. However, this is absolutely not a drawback since the MWCNT were already modified by the grafted initiators (MWCNT-Br) so that SI-ATRP could still progress until completion in suspension rather than at the surface of the Si wafers. Indeed, electrochemical modification by the diazonium salts was effective on each individual nanotube because these were separated by about $100 \mathrm{~nm}$ from each other. Such a gap between the MWCNT-Br nanotubes is large enough to allow the growth of polymer brushes by SIATRP.

\subsection{Characterization}

High resolution TEM was performed on a JEOL 2010 microscope at $200 \mathrm{kV}$. For grid preparation, samples were dispersed in absolute ethanol using an ultrasonic bath. A droplet of solution was deposited on a lacey carbon grid.

XP spectra were recorded using a Thermo VG Scientific ESCALAB 250 system fitted with a micro-focused, monochromatic Al Kot X-ray source $(1486.6 \mathrm{eV}, 650 \mu \mathrm{m}$ spot size) and a magnetic lens which increases the sensitivity. The pass energy was set at 150 and $15 \mathrm{eV}$ for the survey and the narrow regions, respectively. The detached raw and modified MWCNT were mounted on sample holders.

\section{Results and discussion}

MWCNT-polymer hybrids were obtained in two steps. First, ATPR initiators were grafted on the MWCNT surface, second PS and PMMA chains were grafted by SI-ATRP from the surface of MWCNT-Br specimens. The overall synthesis process is illustrated in Scheme 1.

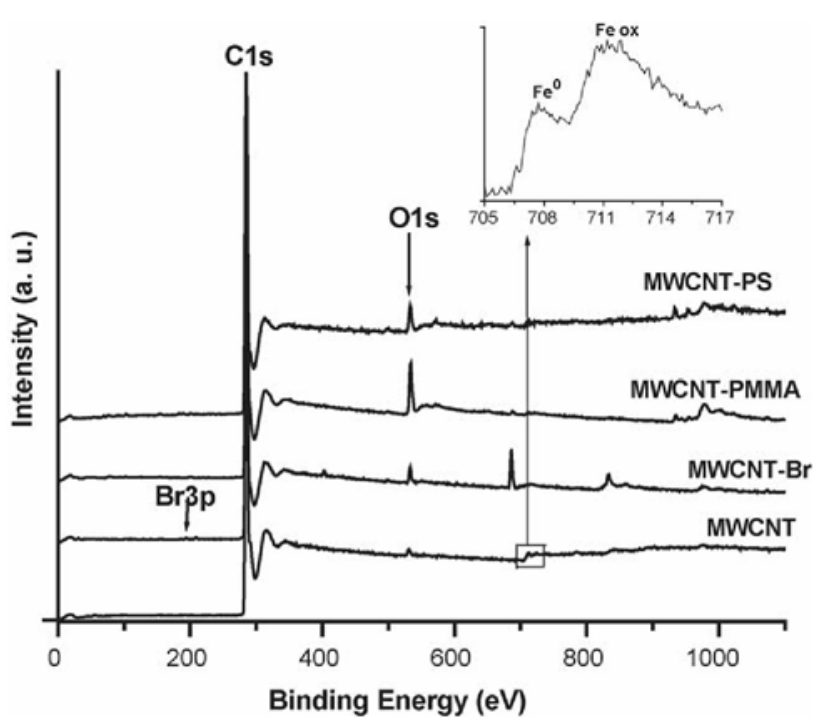

Fig. 2. Survey scans of MWCNT, MWCNT-Br, MWCNT-PS and MWCNTPMMA. 

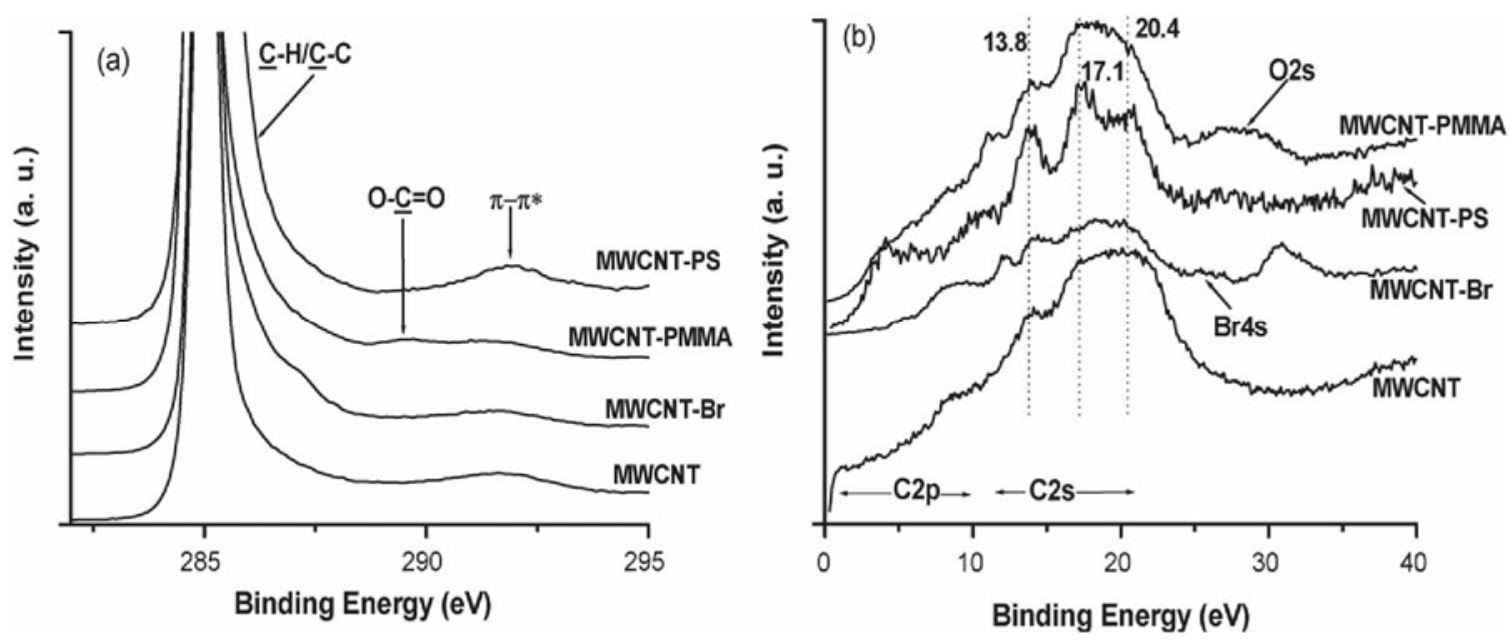

Fig. 3. High-resolution spectra for MWCNT, MWCNT-Br, MWCNT-PMMA and MWCNT-PS. C1s (a), and valence band (b) regions.

The morphology and structure of the pristine and modified MWCNTs was examined by HRTEM and the surface chemical composition by XPS.

In order to compare the surface morphology and structure of the carbon nanotubes before and after growth of polymer chains, raw MWCNT, MWCNT-PS and MWCNT-PMMA were observed (Fig. 1). For raw MWCNTs, the external surface of the nanotubes is well crystallised and corresponds to graphene layers (Fig. 1a). On the contrary, it is obvious that surfaces of MWCNT-PMMA or MWCNT-PS are covered by an amorphous layer exhibiting a thickness between 1 and $2 \mathrm{~nm}$ (Fig. 1b and c). These layers correspond to the grafted polymer chains. This result demonstrates the efficient grafting of PS or PMMA by ATRP on each individual MWCNT. When observing several nanotubes, it is important to note that the distribution of polymer layer is homogeneous along the nanotubes for grafted PS. However, the PMMA layer is locally disrupted.

Structural surface characterization of the modified carbon nanotube surface was undertaken by means of high resolution X-ray photoelectron spectroscopy. Fig. 2 shows the survey scans together with the main peak assignment.

The pristine MWCNT exhibits Fe2p3/2 peak at $710 \mathrm{eV}$ which originates from the ferrocene precursor. The high resolution $\mathrm{Fe} 2 \mathrm{p}$ region displayed in inset, indicates the presence of metallic iron confirming published structural results obtained by X-ray scattering measurements performed on individual carbon nanotube carpets [26].

For the MWCNT-Br, the $\mathrm{Br} 3 \mathrm{~d}$ and ${ }_{\mathrm{Br} 3 \mathrm{p} 3 / 2}$ centred at 70 and $187 \mathrm{eV}$, respectively, are assigned to the grafted brominated aryl groups. The binding energies (BE) are characteristic of $\mathrm{CBr}$ chemical bonds. The F1 s peak centred at $685.1 \mathrm{eV}$ is due to $\mathrm{BF}_{4-}$ from the diazonium salt which could not be removed despite a thorough rinsing.

Interestingly, the $\mathrm{O} 1 \mathrm{~s}$ peak is more intense for MWCNT-PMMA than for MWCNT-PS since the former polymer contains oxygen atoms but not PS. For MWCNT-PS, the $\mathrm{O} 1 \mathrm{~s}$ region arises only from the underlying nanotubes.

The high resolution $\mathrm{C} 1 \mathrm{~s}$ and valence band regions are shown in Fig. 3. MWCNT exhibits a main C1s peak at $285 \mathrm{eV}$ and a shake-up satellite around $291.5 \mathrm{eV}$. The oxidized carbon atoms induce a shoulder in the 286-288 eV range. MWCNT-Br exhibits a more localized shake-up satellite peak and an important component at $286 \mathrm{eV}$ partially due to $\mathrm{CBr}$ bonds.

For MWCNT-PMMA hybrid the occurrence of the polymer is confirmed by the peak at $289 \mathrm{eV}$ due to the OCO carbon from the repeat units. For MWCNT-PS, the $\mathrm{C} 1 \mathrm{~s}$ region exhibits a main $\mathrm{C} 1 \mathrm{~s}$ peak at $285 \mathrm{eV}$ that is slightly broader than that of the carbon nanotube due to the insulating nature of the polymer. In addition, the shake-up satellite at $291.5 \mathrm{eV}$ is very well defined and in line with published data [27].

As far as the valence band regions are concerned (Fig. 3b), the MWCNT are characterized by a broad band around $20 \mathrm{eV}$ BE whereas the MWCNT-Br exhibits a $\mathrm{Br} 4 \mathrm{~s}$ peak at $26 \mathrm{eV}$; note also $\mathrm{F} 2 \mathrm{~s}$ at $30 \mathrm{eV}$ due to $\mathrm{BF}_{4}$. The remarkable resolution available in the valence band reveals subtle molecular structure differences in the $\mathrm{C} 2 \mathrm{~s}$ and $\mathrm{C} 2 \mathrm{p}$ regions between the MWCNT-PMMA and MWCNT-PS reflected in the changes observed in the $\mathrm{C} 1 \mathrm{~s}$ regions discussed above. For MWCNT-PMMA, the valence band displays a broad band at $27 \mathrm{eV}$ due to $\mathrm{O} 2 \mathrm{~s}$ from the acrylate groups and another broad and unresolved band centred at ca. $17.5 \mathrm{eV}$, as currently observed for pure PMMA [28]. MWCNT-PS hybrids exhibits three C2s peaks centred at $13.8,17.1$ and $20.4 \mathrm{eV}$ the BE positions of which match those published for a pure and thick solvent-cast PS film [27,29].

Interestingly, the valence band spectral regions near the Fermi level (about $0.4 \mathrm{eV}$ ), show the evolution between a conducting (pristine MWCNT) and an insulating (MWCNT-PMMA) sample characterized by a few eV gap.

\section{Conclusion}

The present study demonstrates, for the first time, that the "diazonium salt/ATRP" process is a simple, efficient and valuable way of surface modification of carbon nanotubes by tethered polymer brushes. This process involves two steps. First, the surface of MWCNTs is modified by electrochemical reduction of brominated aryl diazonium salts within a few minutes at room temperature. Second, we gave evidences that such modified 
face provides a valuable platform for the surface grafting of polymers, namely PS and PMMA, by ATRP. The tethered polymer chains constitute dense organic adlayers at the surface of MWCNTs.

This communication highlights aryl diazonium salts as versatile building blocks for the development of novel hybrid carbon nanotube-polymer interfaces. Such assemblies are potentially interesting for numerous carbon nanotube applications such as electronic devices and sensors, but also for the preparation of novel composite materials. In the latter application, the grafted polymer brushes would serve as conversion layers for improving the dispersion of the as-modified carbon nanotubes (discontinuous phase) in the host organic polymer matrices (continuous phase).

\section{Acknowledgement}

MMC and MD wish to thank Dr. J. Gooding (University of New South Wales, Australia) for helpful discussion.

\section{References}

[1] B. Zhao, W. Brittain, Prog. Polym. Sci. 25 (2000) 677.

[2] S. Edmondson, V.L. Osborne, W.T.S. Huck, Chem. Soc. Rev. 33 (2004) 14.

[3] S. Palacin, C. Bureau, J. Charlier, G. Deniau, B. Mouanda, P. Viel, Chem. Phys. Chem. 5 (2004) 1468.

[4] E.P.K. Currie, W. Norde, M.A. Cohen Stuart, Adv. Colloid Interface Sci. 100-102 (2003) 205.

[5] K. Matyjaszewski, J. Xia, Chem. Rev. 101 (2001) 2921.

[6] K. Matyjaszewski, S. Qin, J.R. Boyce, D. Shirvanyants, S.S. Sheiko, Macromolecules 36 (2003) 1843.

[7] C. Perruchot, M.A. Khan, A. Kamitsi, S.P. Armes, T. von Werne, T.E. Patten, Langmuir 17 (2001) 4479.

[8] F.J. Xu, S.P. Zhong, L.Y.L. Yung, Y.W. Tong, E.T. Kang, K.G. Neoh, Biomaterials 27 (2006) 1236.

[9] X. Wei, X. Li, S.M. Husson, Biomacromolecules 6 (2005) 1113.
[10] C.Y. Hong, Y.Z. You, D. Wu, Y. Liu, C.Y. Pan, Macromolecules 38 (2005) 2606.

[11] D.M. Jones, J.R. Smith, W.T.S. Huck, C. Alexander, Adv. Mater. 14 (2002) 1130.

[12] Q.J. Cai, G.D. Fu, F.R. Zhu, E.T. Kang, K.G. Neoh, Angew. Chem. Int. Ed. 44 (2005) 1104.

[13] S.M. Desai, S.S. Solanky, A.B. Mandale, K. Rathore, R.P. Singh, Polymer 44 (2003) 7645.

[14] X. Chen, S.P. Armes, Adv. Mater. 15 (2003) 1558.

[15] D. Bontempo, H.D. Maynard, J. Am. Chem. Soc. 127 (2005) 6508.

[16] T. Matrab, M.M. Chehimi, C. Perruchot, A. Adenier, A. Guillez, M. Save, B. Charleux, E. Cabet-Deliry, J. Pinson, Langmuir 21 (2005) 4686.

[17] T. Matrab, M.M. Chehimi, J.P. Boudou, F. Benedic, J. Wang, N.N. Naguib, J.A. Carlisle, Diamond Related Mater., available online on http://www.sciencedirect.com/.

[18] T. Matrab, M.M. Chehimi, J. Pinson, S. Slomkowski, T. Basinska, Surf. Interface Anal. 38 (2006) 565.

[19] J. Pinson, F. Podvorica, Chem. Soc. Rev. 34 (2005) 429, and references therein.

[20] P. Allongue, M. Delamar, B. Desbat, O. Fagebaume, R. Hitmi, J. Pinson, J.M. Sav'eant, J. Am. Chem. Soc. 119 (1997) 201.

[21] E. Coulon, J. Pinson, J.D. Bourzat, A. Commerc on, J.P. Pulicani, J. Org. Chem. 67 (2002) 8513.

[22] J. Wang, M.A. Firestone, O. Auciello, J.A. Carlisle, Langmuir 20 (2004) 11450.

[23] (a) J.L. Bahr, J. Yang, D.V. Kosynkin, M.J. Bronikowski, R.E. Smalley, J.M. Tour, J. Am. Chem. Soc. 123 (2001) 6536;

(b) C.A. Dyke, J.M. Tour, J. Phys. Chem. A 108 (2004) 11151;

(c) P.R. Marcoux, P. Hapiot, P. Batail, J. Pinson, New J. Chem. 28 (2004) 302.

[24] S.E. Kooi, U. Schlecht, M. Burghard, K. Kern, Angew. Chem. Int. Ed. 41 (2002) 1353

[25] M. Pinault, V. Pichot, H. Khodja, P. Launois, C. Reynaud, M. MayneL'Hermite, Nano Lett. 5 (2005) 2394.

[26] V. Pichot, P. Launois, M. Pinault, M.M. L'Hermite, C. Reynaud, Appl. Phys. Lett. 85 (2004) 473.

[27] G. Beamson, D. Briggs (Eds.), High Resolution XPS of Organic Polymers. The Scienta ESCA300 Database, John Wiley, Chichester, 1992.

[28] E.A. Thomas, J.E. Fulghum, J. Vac. Sci. Technol. A 16 (1998) 1106.

[29] S. Turgeon, R.W. Paynter, Thin Solid Films 394 (2001) 43. 